\title{
Earthquake behaviour of a reinforced concrete building constructed in 1933 before and after its repair
}

\author{
G. C. Manos \& E. Papanaoum \\ Laboratory of Strength of Materials and Structures, \\ Department of Civil Engineering, \\ Aristotle University of Thessaloniki, Greece
}

\begin{abstract}
The earthquake behaviour of a four-storey reinforced concrete $(\mathrm{R} / \mathrm{C})$ building, which was constructed in 1933, is investigated here, before and after a recent maintenance and retrofitting. The numerically predicted earthquake behaviour of the initial structure, under the provisions of the current Greek Seismic Code, demonstrated the low resistance of this building to the design seismic loads. The estimate of the strength of existing structural members was based on specific tests performed in-situ as well as at the Laboratory of Strength of Materials and Structures, Aristotle University. The retrofitting scheme included the strengthening of vertical structural elements by jacketing, as well as the use of carbon fibre reinforced plastics (CFRP) for the improvement of the bearing capacity of the slabs. The numerically predicted earthquake behaviour of the retrofitted structure demonstrated the sufficient resistance of the retrofitted building.
\end{abstract}

Keywords: retrofitting, old reinforced concrete building, anchorage of CFRP sheets, improvement of flexural behaviour.

\section{Introduction}

This particular building is a four-storey reinforced concrete $(\mathrm{R} / \mathrm{C})$ building with a basement located at the central plaza of the city of Kozani in Greece. Its construction commenced in 1931 under the design and supervision of the German Engineer Max Ruthven; the owner was a local merchant (K. Vamvakas) 
and it became the best hotel of the region for a number of years (Hotel Ermionio). It is representative as one of the first $\mathrm{R} / \mathrm{C}$ structures of the region (Western Macedonia) and it has many common architectural features with a similar R/C building that was built at the same period in Nice, France by the same engineer. During the last decade, especially after the strong earthquake sequence of May 1995 that affected the city of Kozani, the building was not in use as it was in need of structural repairs. Moreover, because it was protected under the cultural heritage legislation of Greece, it could not be demolished and rebuilt. What is presented here is not the actual design that was submitted for its structural repair to the local city planning authorities. Instead, it is a numerical investigation based on the actual geometry and structural details of the building prior to and after its repair. Moreover, in assessing the expected earthquake performance of this building, use is made of the provisions of the current Greek Seismic Code in finding estimates of the demands imposed on the structural members. The estimates of the corresponding strengths were based on the actual structural details prior to and after its repair as well as on the findings of a specific set of tests that were conducted either in-situ or in the Laboratory. More information is included in the dissertation of the second author [1].

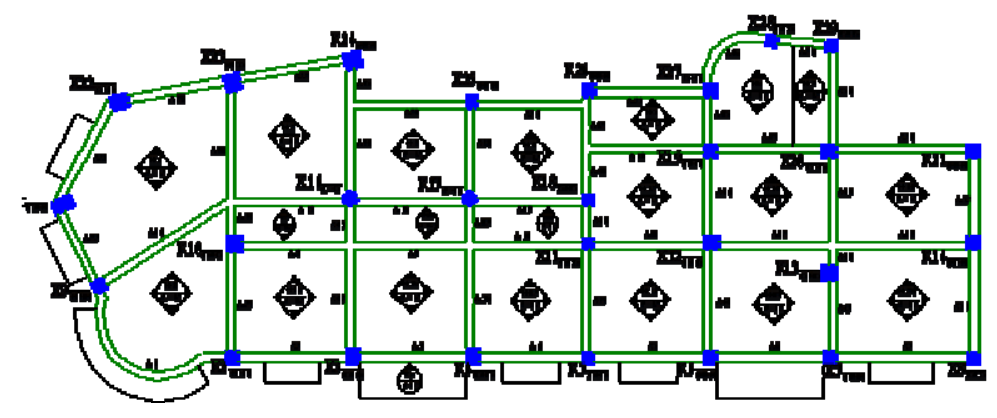

Figure 1: $\quad$ Plan of the typical floor showing the $\mathrm{R} / \mathrm{C}$ columns, beams and slabs.

\section{Assessing the performance prior to the retrofitting}

\subsection{Level A: quick assessment of the old existing building}

This assessment was made according to the guidelines of a relevant assessing method adopted by the Organization of Antiseismic Planning and Protection of Greece [2]. This is a simple method based on general structural features of a building as well as on particular information of its original design. The grading of this building, according to this Level A assessment was relatively low (Total Grade $=-1<0$ ); this is an indication that the building may have a nonsatisfactory earthquake performance and one must proceed to the level B assessment. 


\subsection{Level B: assessment of the old existing building}

For this assessment level one needs to get information on the structural details and material properties, based both on the original design files as well as on insitu information. Moreover; the design assumptions made on the mechanical properties of the materials must be supplemented by information obtained in-situ from the actual structure.

Towards this end, concrete and steel specimens were taken from the slab of the ceiling of the ground floor and were tested at the Laboratory. The average concrete strength found was $11.23 \mathrm{Mpa}$. The corresponding characteristic strength that can be assumed today is $\mathrm{C} 8 / 10\left(\mathrm{f}_{\mathrm{ck}}=8 \mathrm{MPa}\right)$. The reinforcing steel bars were of the smooth surface type with yield stress $\mathrm{f}_{\mathrm{y}}=361 \mathrm{Mpa}$ for the $8 \mathrm{~mm}$ rebar $\left(f_{\text {ult }}=500 \mathrm{Mpa}\right)$ and $\mathrm{f}_{\mathrm{y}}=317 \mathrm{Mpa}$ for the $10 \mathrm{~mm}$ rebar $\left(\mathrm{f}_{\text {ult }}=404 \mathrm{Mpa}\right)$ and elongation at fracture larger than $20 \%$. The corresponding yield stress that can be assumed today is $\mathrm{f}_{\mathrm{y}}=350 \mathrm{Mpa}$.

\subsubsection{Assessing the expected performance of the slabs}

For this purpose an F.E. analysis was performed for all the slabs with predominant loading the combination of dead and live loads as specified by the Greek Code. Figure 2 shows the results of the ground floor ceiling that is one of the most-stressed slabs due to the relatively large exterior balconies and internal verandas as well as from its live load requirements. The extreme values of some of the demands in terms of bending moments are shown in the same figure. The structural detail of this slab is shown in figure 3 .

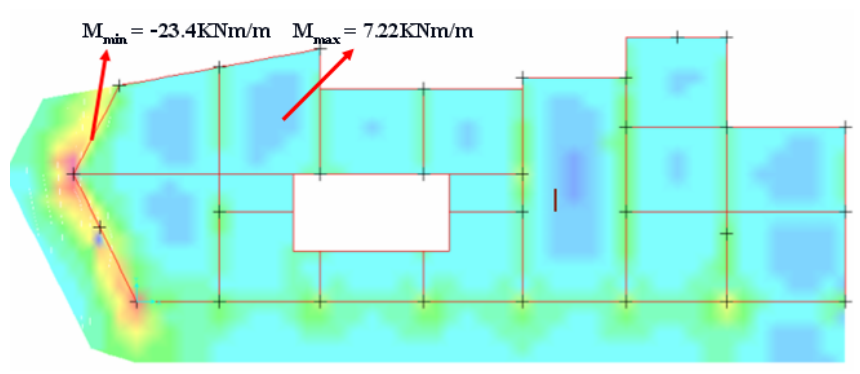

Figure 2: The flexural demands for the ground floor ceiling.

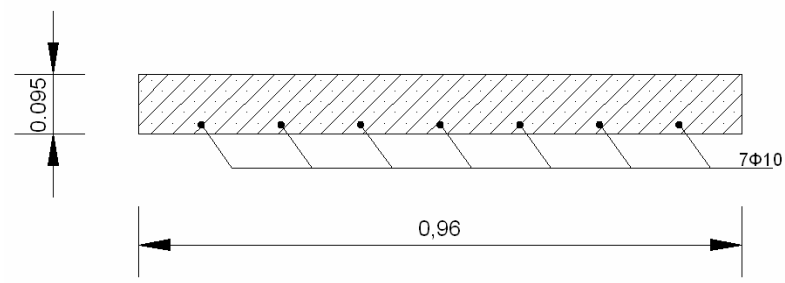

Figure 3: $\quad$ Structural detail of the R/C slab. 
One piece of the slab with dimensions $1.30 \mathrm{~m} \times 0.96 \mathrm{~m}$ was removed from the building and was tested under controlled conditions in pure flexure at the Laboratory, resulting in a bending moment capacity $\mathrm{M}_{\mathrm{Rd}}=9.18 \mathrm{KNm} / \mathrm{m}$. The corresponding estimate based on the structural detail (figure 3) and the relevant calculations is equal to $\mathrm{M}_{\mathrm{Rd}}=11.78 \mathrm{KNm} / \mathrm{m}$. This non-conservative estimate must be attributed to the long term corrosion that reduced the effective crosssection of the reinforcing bars. Comparing the experimental bending slab strength with the numerical analysis maximum demand (figure 2) for positive slab flexure a safety factor equal to 1.27 is found, that indicates an acceptable limit-state performance. However, the demand for negative slab flexure yields a minimum bending moment that is approximately three times larger $(\mathrm{Mmin}=$ $23.4 \mathrm{KNm} / \mathrm{m}$ ), which indicates a non-acceptable limit-state performance for the large exterior balconies. The retrofitting addressed this requirement as will be presented in section 3.1.3.

\subsubsection{Assessing the expected earthquake performance of the multi-storey structure}

A dynamic numerical analysis was performed for this purpose according to the provisions of the Greek Seismic Code 2000 [3], utilizing the capabilities of SAP200- (version 10.1) software. Three different approaches were employed. First, "The simplified spectral method", second, "The Dynamic Spectral Method based on the design spectrum specified by the Greek Seismic Code", third, "The Dynamic Spectral Method based on the response spectrum that resulted from the 1995 Kozani Earthquake" [4]. In figure 5 apart from the acceleration response spectra curves for the two recorded ground acceleration components (East-West, North-South, 5\% damping ratio) the design spectrum curve from the Greek Seismic Code (EAK) is also included. Moreover, the Eigen-periods of the old existing structure as well as of the retrofitted building are also shown.

For the simplified spectral method the following parameters were applied in the numerical analysis:

Eigen-periods $\mathrm{x}-\mathrm{x}, \mathrm{y}-\mathrm{y} \quad \mathrm{T}_{\mathrm{x}}=0.47 \mathrm{sec} ., \mathrm{T}_{\mathrm{y}}=0.483 \mathrm{sec}$.

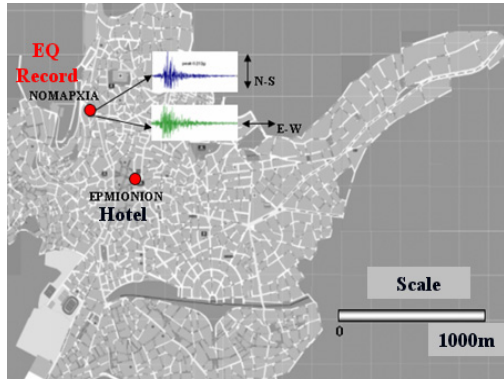

Figure 4: Site of EQ record and location of Hotel Ermionio.

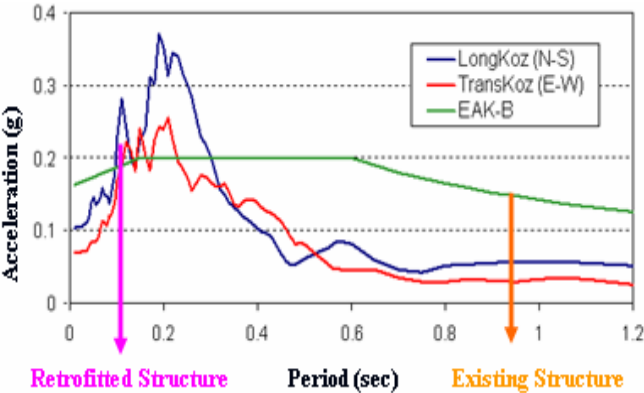

Figure 5: Acceleration response spectrum for the Kozani Earthquake of May 1995. 
Seismic Zone I, design ground acceleration $0.16 \mathrm{~g}$, Soil Category B, Importance Factor $=1$, response modification factor $\mathrm{q}=2.0$, damping ratio $5 \%$, response amplification factor $\beta_{\mathrm{o}}=2.5$, influence of the foundation $\theta=1$

According to the Greek Seismic Code provisions, the original building is a torsionally sensitive structure with design eccentricities equal to:

${ }_{\max } \mathbf{e x}=5.8 \mathrm{~m},{ }_{\max } \mathbf{e y}=1.25 \mathrm{~m},{ }_{\min } \mathbf{e x}=-3.8 \mathrm{~m},{ }_{\min } \mathbf{e y}=-0.75 \mathrm{~m}$.

According to the dynamic spectral 3-D method of analysis the Eigen-period values for the original building that mobilize more than $90 \%$ of the total mass are listed in the following table.

From the modal analysis it becomes apparent that there is a degree of coupling between mode 2 and mode $3 \mathrm{n}$ with modal participation factors that correspond to nearly $75 \%$ of the total mass (see figures 6 and 7).

Figure 8 depicts the flexural demands for the ground floor columns as they resulted from the various analysis approaches briefly described above.

Table 1: $\quad$ Eigen-period values Ti (seconds).

\begin{tabular}{|l|l|l|l|l|l|l|l|l|l|l|l|l|}
\hline T1 & T2 & T3 & T4 & T5 & T6 & T7 & T8 & T9 & T10 & T11 & T12 & T13 \\
\hline 1.51 & 0.96 & 0.94 & 0.54 & 0.33 & 0.33 & 0.27 & 0.16 & 0.16 & 0.16 & 0.12 & 0.09 & 0.09 \\
\hline
\end{tabular}
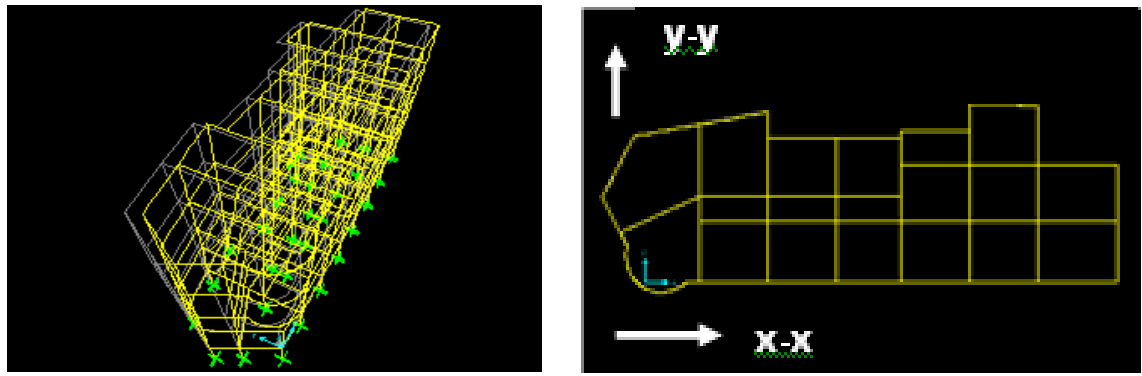

Figure 6: $\quad \mathrm{T} 2=0.96 \mathrm{sec}(70 \%$ mass participation along $\mathrm{y}-\mathrm{y})$.
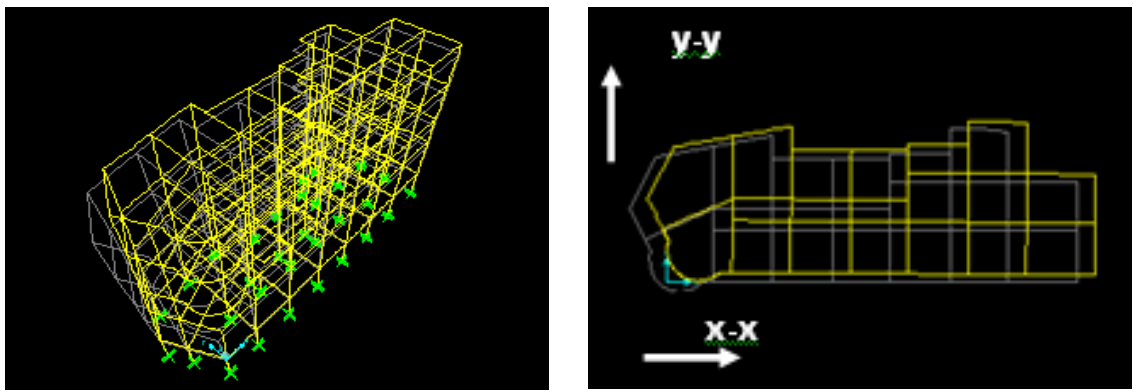

Figure 7: $\quad \mathrm{T} 3=0.94 \sec (70 \%$ mass participation along $\mathrm{x}-\mathrm{x})$. 


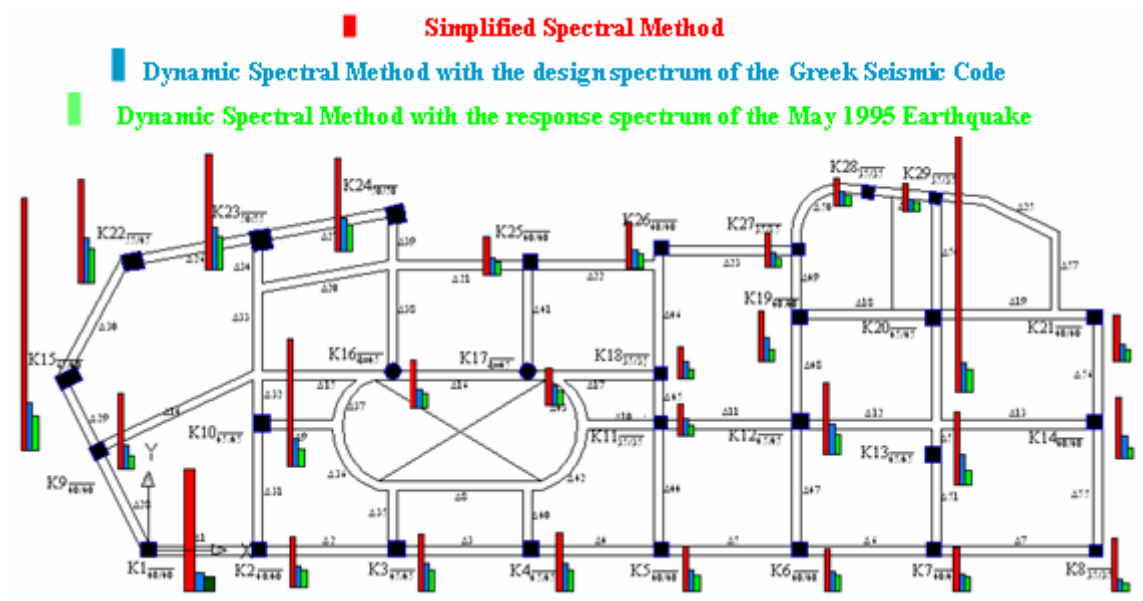

Figure 8: Predictions of the flexural demands for the ground floor columns.

Table 2: $\quad$ Inter-storey drift values for the frame K1-K9-K15-K22 in the south.

\begin{tabular}{|c|c|c|c|c|}
\hline $\begin{array}{c}\text { Angular } \\
\text { Inter-storey } \\
\text { Drift } \\
\gamma\end{array}$ & $\begin{array}{c}\text { Ground Floor } \\
(\mathrm{h}=4.09 \mathrm{~m})\end{array}$ & $\begin{array}{c}\text { Mezzanine } \\
(\mathrm{h}=2.60 \mathrm{~m})\end{array}$ & $\begin{array}{c}1^{\text {st }} \text { storey } \\
(\mathrm{h}=3.60 \mathrm{~m})\end{array}$ & $\begin{array}{c}2^{\text {nd }} \text { storey } \\
(\mathrm{h}=3.75 \mathrm{~m})\end{array}$ \\
\cline { 2 - 5 } & $\mathbf{0 . 0 2 3 3}$ & $\mathbf{0 . 0 2 2 6}$ & $\mathbf{0 . 0 2 1 9}$ & $\mathbf{0 . 0 1 6 6}$ \\
\hline
\end{tabular}

- The simplified spectral method.

- The Dynamic Spectral Method based on the design spectrum specified by the Greek Seismic Code.

-The Dynamic Spectral Method based on the response spectrum that resulted from the 1995 Kozani Earthquake.

As can be seen from figure 8 , the flexural demands resulting from the Simplified Spectral Method are 2 to 6 times larger than the corresponding demands resulting from the Dynamic Spectral Method based on the design spectrum specified by the Greek Seismic Code. This must be attributed to the torsional sensitivity of the old existing structure, which is penalized by the provisions of the Greek Seismic Code when the Simplified Spectral Method is applied. When the results of the Dynamic Spectral Method based on the response spectrum of the 1995 earthquake are compared with the corresponding results based on the design spectrum included in the Greek Seismic Code it can be concluded that the former are 1.25 to 1.75 times smaller than the latter. This must be attributed to the difference in the amplitude of the corresponding design spectral curves when combined with the dominant Eigen-period values of the existing old building (see figure 5).

Table 2 lists the predicted inter-storey drift values, in terms of angular interstorey response, for the various stories of the old existing structure as predicted by the Dynamic Spectral Method based on the design spectrum specified by the Greek Seismic Code. As can be seen these inter-storey drift values are more than 4 times larger than the limit set by the Greek Seismic Code (limit=0.005). When 
the flexural strength capacities of the columns of the old existing building are compared with the flexural demands, predicted as explained before, the demands by far exceed the capacities when these demands are based on the Simplified Spectral Method; when these demands are taken from the Dynamic Spectral Method based on the design spectrum specified by the Greek Seismic Code they exceed the flexural capacities of almost all the Ground Floor columns. The flexural capacities satisfy the demands for the columns of the structure only when the predictions are resulting from the Dynamic Spectral Method based on the response spectrum that resulted from the 1995 Kozani Earthquake. As pointed out, this is due to the frequency content of this particular ground motion combined with the Eigen-frequencies of the old existing structure (figs. 4 and 5).

\section{Structural retrofitting}

The structural retrofitting (figure 9), aimed to upgrade the earthquake performance of the building, included jacketing of all the columns and beams (with a thickness of $75 \mathrm{~mm}$ for the columns and $50 \mathrm{~mm}$ for the beams) as well as the construction of shear-walls (with a thickness of $300 \mathrm{~mm}$ ), within the bays of the old structure at the North and East perimeter of the building that were not obstructing its functioning that could be served from the other two sides (South and West) facing the main square of the city. This retrofitting scheme could serve to increase the torsional stiffness of the structure as well as upgrade the capacities of all the columns; it extended all the way from the foundation to the top of the building. The specified retrofitting materials are C20/25 for the concrete and S500s for the steel. Moreover, the retrofitting included the upgrading of the flexural capacity of the slabs by applying Carbon Fibre Reinforcing Plastic sheets (see section 3.13).

\subsection{Level B assessment of the retrofitted building}

The expected earthquake performance of the retrofitted structure was assessed in the same way as described in section 2.2.2, employing the previously described

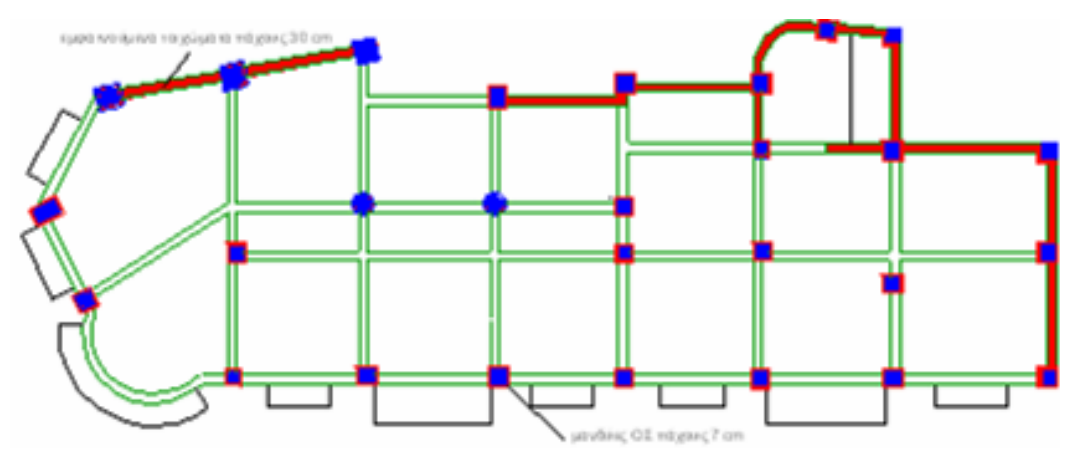

Figure 9: Studied retrofitting scheme. 


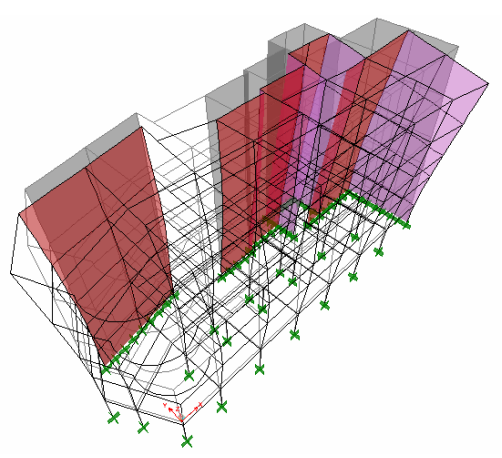

(a)

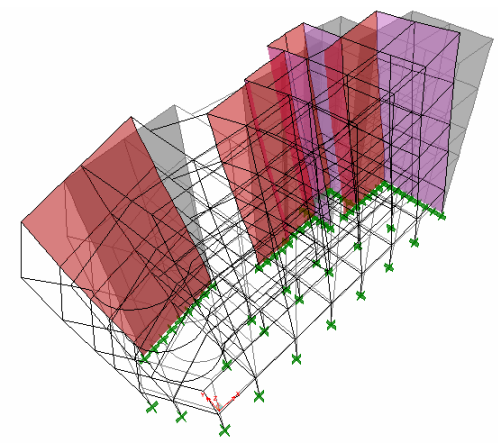

(b)

Figure 10: (a) $\mathrm{T} 2=0.15 \mathrm{sec}(54 \%$ mass participation along $\mathrm{y}-\mathrm{y})$; (b) $\mathrm{T} 9=0.09$ $\sec (56 \%$ mass participation along $\mathrm{X}-\mathrm{x})$.

methods of analysis and numerical tools. In what follows, a summary of this assessment will be presented by comparing critical response parameters of the retrofitted building with those of the existing old building.

\subsubsection{Influence of the retrofitting on the Eigen-modes and Eigen-periods}

In figures 10(a) and 10(b) the dominant Eigen-modes of the retrofitted structure are shown together with the corresponding Eigen-periods, which are also listed in Table 3. As can be seen, the retrofitting scheme resulted in a significant increase of the lateral stiffness of the structure.

Table 3: Comparison of Eigen-period values between old and retrofitted structure.

\begin{tabular}{|c|c|c|}
\hline Structural Scheme & $\begin{array}{c}\text { Eigen-period for } \\
\text { dominant } y-y \text { response }\end{array}$ & $\begin{array}{c}\text { Eigen-period for dominant } \\
\text { x-x response }\end{array}$ \\
\hline Old Structure & $\mathrm{T} 2=0,96 \mathrm{sec}$ & $\mathrm{T} 2=0,15 \mathrm{sec}$ \\
\hline $\begin{array}{c}\text { Retrofitted } \\
\text { Structure }\end{array}$ & $\mathrm{T} 3=0,94 \mathrm{sec}$ & $\mathrm{T} 4=0,09 \mathrm{sec}$ \\
\hline
\end{tabular}

Table 4: $\quad$ Comparison of displacement response between old and retrofitted structure.

\begin{tabular}{|c|c|c|c|c|c|c|}
\hline \multirow{2}{*}{$\begin{array}{c}\text { Top } \\
\begin{array}{c}\text { Storey } \\
\text { Corner }\end{array}\end{array}$} & \multicolumn{3}{|c|}{ Old Existing Building } & \multicolumn{3}{c|}{ Retrofitted Structure } \\
\cline { 2 - 7 } & $\mathbf{u}_{\mathbf{x}} \mathbf{( \mathbf { m m } )}$ & $\mathbf{u}_{\mathbf{y}}(\mathbf{m m})$ & $\boldsymbol{\theta z} \mathbf{( r a d})$ & $\mathbf{u}_{\mathbf{x}}(\mathbf{m m})$ & $\mathbf{u}_{\mathbf{y}}(\mathbf{m m})$ & $\boldsymbol{\theta z}(\mathbf{r a d})$ \\
\hline $\mathbf{S}-\mathbf{W}$ & 51,36 & 56,99 & $3,64 \cdot 10^{-4}$ & 0,62 & 5,79 & $1,33 \cdot 10^{-4}$ \\
\hline $\mathbf{N}-\mathbf{W}$ & 51,10 & 47,37 & $5,87 \cdot 10^{-4}$ & 0,95 & 1,50 & $2,47 \cdot 10^{-4}$ \\
\hline $\mathbf{N}-\mathbf{E}$ & 50,34 & 47,37 & $7,08 \cdot 10^{-4}$ & 2,51 & 1,50 & $3,57 \cdot 10^{-4}$ \\
\hline S-E & 50,30 & 56,51 & $8,28 \cdot 10^{-4}$ & 2,64 & 5,54 & $3,45 \cdot 10^{-4}$ \\
\hline
\end{tabular}




\subsubsection{Influence of the retrofitting scheme on the maximum displacement and stress response}

The influence of the retrofitting scheme is studied by comparing the maximum response values, in terms of displacements and stress-resultant values relevant to flexural response of the columns, resulting by applying the Dynamic Spectral Method based on the design spectrum specified by the Greek Seismic Code.

As can be seen in table 4, the increase in the lateral stiffness of the structure resulted in a drastic decrease of the horizontal displacement response at the ceiling of the third storey (top of the building). This decreased occurred despite a relative increase in the lateral seismic forces resulting from the increase of the spectral values corresponding to the dominant Eigen-modes of the retrofitted structure when compared with those of the old existing structure (figure 4). This is also true for the stress-resultant response values relevant to flexure of the columns. These maximum response values are listed in table 5 for all the columns of the Ground Floor before and after retrofitting. As can be seen this maximum response is reduced by 2 to 4 times by the applied retrofitting scheme. A critical element in the applied retrofitting is the strengthening of the existing foundation. A critical parameter here was the fact that the foundation was above the water-level as well as it could be extended all-around the perimeter of the building. Moreover, the existing footings could be supplemented with extra layer applied from their top, together with beams that could link the columns springing from these footings and the reinforcing cages that formed the jacketing of these columns starting from this level and extending all the way to the top of the building. The reduced flexural demands for the columns resulting from the applied retrofitting scheme combined with the increased capacities of the structural elements due to the presence of the jacketing, which was constructed in all the structural elements (columns and beams) as briefly described in the beginning of this section, lead to a satisfactory earthquake performance of this building after retrofitting.

Table 5: Comparison of stress-response between old and retrofitted structure.

\begin{tabular}{|c|c|c|c|c|c|c|}
\hline \multirow{2}{*}{$\begin{array}{c}\text { Ground } \\
\text { Floor } \\
\text { Column No }\end{array}$} & \multicolumn{3}{|c|}{ Old Existing Building } & \multicolumn{3}{c|}{ Retrofitted Structure } \\
\cline { 2 - 7 } & $\mathbf{N}(\mathbf{k N})$ & $\begin{array}{c}\mathbf{M}_{\mathbf{2}} \\
\mathbf{( k N} \cdot \mathbf{m})\end{array}$ & $\begin{array}{c}\mathbf{M}_{\mathbf{3}} \\
\mathbf{( k N} \cdot \mathbf{m})\end{array}$ & $\mathbf{N} \mathbf{( k N )}$ & $\begin{array}{c}\mathbf{M}_{\mathbf{2}} \\
(\mathbf{k N} \cdot \mathbf{m})\end{array}$ & $\begin{array}{c}\mathbf{M}_{\mathbf{3}} \\
(\mathbf{k N} \cdot \mathbf{m})\end{array}$ \\
\hline $\mathbf{2 6 6}$ & 89.92 & 108.91 & 121.09 & 30.48 & 51.39 & 38.11 \\
\hline $\mathbf{2 6 7}$ & 246.90 & 104.47 & 131.70 & 73.32 & 36.57 & 24.51 \\
\hline $\mathbf{2 7 9}$ & 180.76 & 103.21 & 134.29 & 38.03 & 16.79 & 25.93 \\
\hline $\mathbf{2 8 7}$ & 269.94 & 114.20 & 120.19 & 53.06 & 5.58 & 25.29 \\
\hline $\mathbf{2 9 1}$ & 197.96 & 76.08 & 64.14 & 102.71 & 4.17 & 10.69 \\
\hline $\mathbf{2 9 9}$ & 311.10 & 150.70 & 79.06 & 151.79 & 71.05 & 3.65 \\
\hline $\mathbf{3 2 3}$ & 74.65 & 141.96 & 87.03 & 25.82 & 1.24 & 3.46 \\
\hline $\mathbf{3 2 7}$ & 317.95 & 166.11 & 297.42 & 64.46 & 71.53 & 35.21 \\
\hline $\mathbf{3 4 7}$ & 81.33 & 182.72 & 173.28 & 2.97 & 0.06 & 2.31 \\
\hline $\mathbf{3 5 1}$ & 205.96 & 107.81 & 92.76 & 211.63 & 13.02 & 9.30 \\
\hline $\mathbf{2 6 6}$ & 89.92 & 108.91 & 121.09 & 30.48 & 51.39 & 38.11 \\
\hline
\end{tabular}




\subsubsection{Upgrading the flexural capacity of the slabs}

As described in section 2.2.1. the assessment of the expected performance of the slabs revealed that they were in need of being upgraded regarding their flexural capacity. Towards this objective, a retrofitting scheme was investigated to be applied to these slabs. This scheme was planned to make use of a certain type of Carbon Fibre Reinforcing Plastic sheets (CFRP) with a cross-section 50mm x $1.2 \mathrm{~mm}$. These sheets were of the hardened type and they could be applied on the upper or lower surface of the concrete slabs with the use of a special epoxy paste. Figure 11 depicts the obtained flexural behaviour of an Ermionio slab specimen tested at the laboratory being retrofitted with two sheets of the previously described CFRP's. Initially, the CFRP sheets were attached to the specimen only with the epoxy past and the specimen was loaded up to its limit-state (figure 11, $20.89 \mathrm{KNm} / \mathrm{m}$ ), which appeared in the form of the unbonding of the CFRP sheets (figure 12) and the loss of the bearing capacity of the slab. Next, the two CFRP layers were reattached to the concrete slab specimen; this time epoxy paste was used again together with bolts penetrating through the slab and securing the attachment of the CFRP layers. An extensive parametric study was performed on this type of attachment by testing a series of specimens prior to applying the best attachment detail to the slab specimen. The bearing capacity of the slab specimen reached the same limit-state levels as before, despite its previous loading history; however; this time the attachment of the CFRP sheets was satisfactory and the flexural behaviour of the slab exhibited a much larger range of deformability.

\section{Conclusions}

1. From the assessment of the old existing building it was demonstrated that it could lead to an expected unsafe earthquake performance, especially for the Ground Floor columns. This unsatisfactory performance was also demonstrated for the slab of the Ground Floor ceiling.

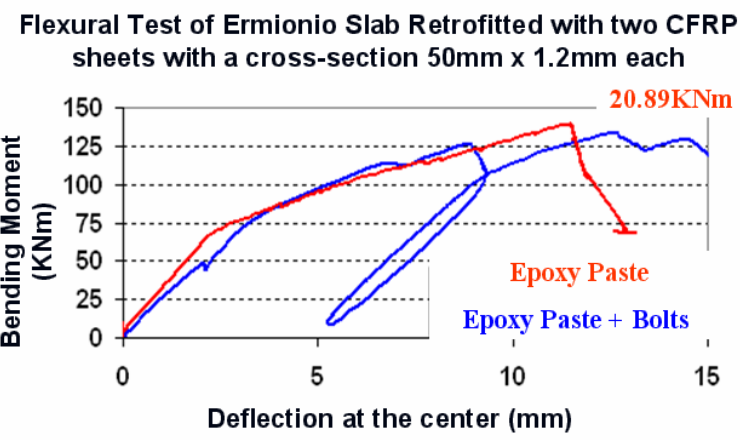

Figure 11: The flexural behaviour of an Ermionio slab specimen retrofitted with two CFRP sheets. In the first case the CFRP was attached only with epoxy paste, in the second case the CFRP was attached with epoxy paste and bolts. 


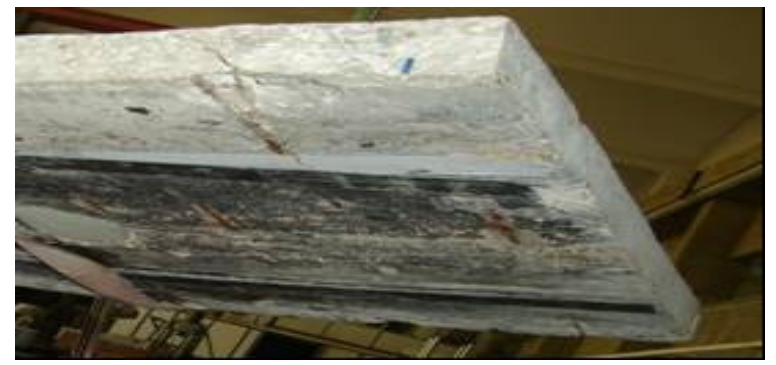

Figure 12: Failure of the flexural behaviour of an Ermionio slab specimen retrofitted with two CFRP sheets. The CFRP sheets were unbonded from the concrete slab.

2. A retrofitting scheme was investigated for the structure which was demonstrated to be successful in meeting the demands specified by the current Seismic Code of Greece.

3. This retrofitting scheme was supplemented with a scheme to upgrade the flexural capacity of the slabs by applying a certain type of CFRP sheets; the upgrade capability of this later scheme was validated by laboratory tests.

4. The building is already retrofitted and in use again.

\section{References}

[1] E. Papanaoum, "Estimate of the EQ performance of a 4-storey R/C building before and after retrofitting", Dept. Civil. Eng., Aristotle Univ., 2006.

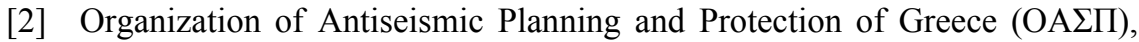
"The Seismic Code of Greece", Athens 2000.

[3] $(\mathrm{OA} \Sigma \Pi)$, «Guidelines for Level - An earthquake performance checking of buildings of public occupancy», Athens 2001.

[4] European Strong Motion Database, The Kozani Earthquake 1995. 